\section{Entrepreneurial crowdfunding backer motivations: a latent Dirichlet allocation approach}

Entrepreneurial crowdfunding backer motivations

Jeremy St John

Management and Marketing, Angelo State University, San Angelo, Texas, USA

Karen St John

School of Information Technology and Computing, Abilene Christian University, Abilene, Texas, USA, and

Bo Han

Marketing and Business Analytics, Texas A\&M University Commerce, Commerce, Texas, USA

\begin{abstract}
Purpose - This study furthers one's understanding of the motivations of the crowdfunding crowd by empirically examining critical factors that influence the crowd's decision to support a crowdfunding project. Design/methodology/approach - Backer's comments from a sample of the top 100 most funded technology product projects on KickStarter were collected. A latent Dirichlet allocation (LDA) analysis strategy was adopted to investigate critical motivational factors. Three experts mapped those factors to the known theoretical constructs of social exchange theory (SET).

Findings - Although backers are motivated by value, they are also motivated by far less tangible social factors including trust and a feeling of psychological ownership. Findings suggest that the crowd is far more than a passive group of investors or customers and should be viewed as participatory stakeholders. This study serves as guidance for project owners hoping to motivate the crowd and for future investigators examining backer motivations in other types of crowdsourcing projects.

Research limitations/implications - Online chatter in the form of user-generated comments is an excellent data source for researchers to mine for value and meaning.

Practical implications - Given strong feelings of psychological ownership, project owners should actively engage the crowd and solicit the crowd for advice and help in order to motivate them.

Originality/value - The study presents the first empirical exploration of backer motivations using LDA guided by theory and the knowledge of experts. A framework of latent motivational factors is proposed.

Keywords Social exchange theory, Motivation (psychology), Psychological ownership, Crowdfunding, Latent Dirichlet allocation
\end{abstract}

Paper type Research paper

\section{Introduction}

Crowdsourcing has been described as a source for innovation (Brem et al., 2019). Crowdfunding is a specific type of crowdsourcing focused on obtaining funding for a project (Li et al., 2020). In this study we examine a specific type of crowdfunding known as rewards-based crowdfunding (e.g. Kickstarter). Rewards-based crowdfunding is characterized by entrepreneurial project owners compensating backers with some tangible nonfinancial reward, often an example of the product, while retaining full ownership of the

(C) Jeremy St John, Karen St John and Bo Han. Published by Emerald Publishing Limited. This article is published under the Creative Commons Attribution (CC BY 4.0) licence. Anyone may reproduce, distribute, translate and create derivative works of this article (for both commercial and non-commercial purposes), subject to full attribution to the original publication and authors. The full terms of this licence

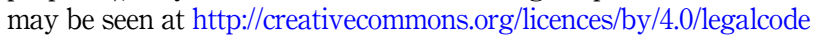

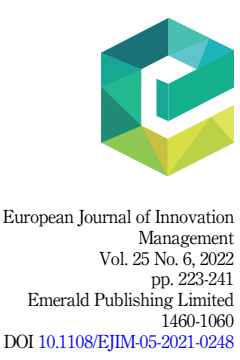


EJIM

25,6

project ( $\mathrm{Li}$ and Wang, 2019). The large number of individuals "out there" on the Internet is commonly referred to as the crowd and "tapping the right crowd" for funding without going through institutional financial intermediaries (e.g. investment banks) is the key feature that differentiates crowdfunding from traditional fundraising (Belleflamme et al., 2014). The term "backers" is used to describe individuals in the online "crowds" who offer financial support to projects creators (Frydrych et al., 2014; Zhang and Chen, 2018).

The practice of using the crowd to fund a project is not new. More than a century ago, crowdfunding was used to finance influential projects including the Statue of Liberty's pedestal (Joseph Pulitzer, 2015). Churches have been appealing to the crowd for funding for centuries. Although crowdfunding is not new, what is new are the enabling Internet technologies and the innovative application of those technologies used to reach the crowd and appeal for support. These technologies and their application have enabled what Belleflamme et al. (2014) refer to as an open call via the Internet, which replaced earlier open calls via the newspaper or pulpit. The result of this has been a different kind of crowd fueling the exponential growth of crowdfunding as an important funding source for entrepreneurial businesses (Burtch et al., 2013; Zheng et al., 2014).

Getting consumers involved in innovation has been cited as a decades-old need that is now possible with new technologies such as crowdfunding (Burger-Helmchen et al., 2020; Busse and Siebert, 2018). Technology-driven crowdfunding has transformed and expanded not only the crowd but also those who would appeal to the crowd. Startups and individuals focused on innovation in particular have been historically excluded. One reason is, because of their innovative nature, innovative projects are difficult to compare against similar past projects when evaluating risk and likelihood of success. That uncertainty has historically excluded such projects from traditional funding. Crowdfunding is considered part of the "sharing economy" (Lamphere, 2018, p. 1) because it democratizes access to capital for innovative startups and others historically excluded from access to funding. (Mollick and Robb, 2016).

Crowdfunding is an emerging and important funding source that has attracted the interest of scholars and practitioners alike as it has grown exponentially, now raising tens of billions of dollars annually (Hossain and Oparaocha, 2017; Li et al., 2020; Short et al., 2016). Globally, the crowdfunding market had a value of $\$ 8.54 \mathrm{bn}$ in 2020 and is expected to be worth $\$ 11.98$ bn by 2023 (Learnbonds.com, 2020).

Many factors related to crowdfunding success have been investigated (Courtney et al., 2016; De Crescenzo et al., 2020; Lukkarinen et al., 2016; Yuan et al., 2016). However, we still know relatively little about why the online crowd supports or fails to support specific crowdfunding projects (Allison et al., 2017; Keongtae and Viswanathan, 2019; Lehner et al., 2015). In examining entrepreneurial reasons for crowdfunding motivations, Lehner et al. (2015) determined that entrepreneurship viewpoints are not sufficient to explain crowdfunding motivations and recommended that future research look at crowdfunding motivations from multiple perspectives. What motivates and influences this mysterious, seemingly anonymous and heterogeneous crowdfunding crowd is not well understood and what influences their decisions is difficult to measure and verify. There have been several calls to investigate the crowd's motivations for supporting crowdfunding projects (Bretschneider et al., 2014; Gerber and Hui, 2013; Lehner, 2013; Moritz and Block, 2014). Since then studies have found noneconomic motivations for backing a project including collecting rewards, helping people and being part of a community or project (Bretschneider and Leimeister, 2017; Cholakova and Clarysse, 2015; Gerber and Hui, 2013). In their exploratory survey of 309 crowdfunding backers, Bretschneider and Leimeister concluded that research on backers' motivations was "at an embryonic stage and understanding of the motivation for participation in incentive-based crowdfunding is incomplete" (2017, p. 11). Ribeiro-Navarrete et al. (2021) identified a lack of literature on the importance of communication as a factor for backer satisfaction. Li and Wang (2019) found that the 
current evidence in the literature on backer motivations was based on self-reported survey data and showed inconsistent findings.

It has been noted that crowdfunding success remains elusive and the percentage of successfully funded projects is actually very low (Barnett, 2013; Burtch et al., 2013; Mollick, 2014). Only about $20 \%$ of all proposed projects eventually reach their funding goals by the deadlines on the crowdfunding website IndieGoGo.com, and only about a third reach their goals on KickStarter (Barnett, 2013). However, under the technology project category, the success rate is lower. In 2015 , only $20 \%$ of all proposed technology projects eventually reached their funding goals on KickStarter. In 2019, the success rate of proposed technology projects was essentially the same at $20.45 \%$, lower than all other KickStarter categories (Kickstarter.com, 2019). In a survey of a different kind of crowd, namely collaborative workforces, Kleemann and Voss (2008) noted that crowdsourcing strategies require significant investments in time and money, with success completely dependent on the response of the crowd. Also with crowdfunding, project owners report that crowdfunding demands significant time and effort (Hui et al., 2014). Questions such as who are the people that make up the online "crowd" and what motivates them to pledge funds to crowdfunding projects are interesting. A better understanding of the motivations of the backers supporting crowdfunding projects, as provided by this study, can shed light on these questions and be valuable from both an academic and a practitioner point of view.

$R Q$. What latent factors motivate the crowd's decision to pledge funds to technology crowdfunding projects?

The question of what motivates backers is difficult to answer. Asking backers directly what motivates them is especially difficult since they likely do not know or remember. Still, it is an important question and the answers should inform most everything the project owner does. In the groundbreaking work "The Crowd," LeBon (1896) describes crowds as always being unconscious and unconsciousness as being one of the secrets of the strength of the crowd. In this study we examine the hidden motivations of the crowd using modern text analysis. Our study contributes to the literature on backer motivations in reward-based crowdfunding (e.g. Bretschneider and Leimeister, 2017; Cholakova and Clarysse, 2015; Gerber and Hui, 2013; Li and Wang, 2019). This paper presents the first empirical exploration of backer motivations using latent Dirichlet allocation (LDA) guided by social exchange theory (SET) and the knowledge of experts.

In the next section we discuss the theoretical underpinnings of this research. Section 3 describes the research methodology employed to analyze backer comments to extract topics for analysis. Section 4 presents the results. Section 5 offers a discussion of results, maps topics to SET and highlights relevant findings. Section 6 concludes the study and offers suggestions for project owners seeking to motivate the crowd.

\section{Literature review and theoretical background}

\subsection{Crowdfunding}

Crowdfunding, as a determinant of success through funding, has become very influential in fields such as music production (Martinez-Canas et al., 2012) and charity fundraising (Meer, 2014). Crowdfunding has also become an important incubator for new entrepreneurial projects particularly given past economic contractions. Crowdfunding for entrepreneurial purposes is different than, for instance, charity fundraising and is supported by different types of crowds and crowdfunding platforms. KickStarter is a platform associated with entrepreneurial projects in design and technology categories, to name a few. This study focused on backers of entrepreneurial projects and follows the example set by Mollick (2014) by limiting our study to successful projects in the design and technology categories hosted by 
EJIM

25,6

KickStarter. According to their website, KickStarter, one of the largest crowdfunding web sites in the world, has raised over $\$ 1.8 \mathrm{bn}$ for new design and technology projects as of July 2019. With the support of crowdfunding, several projects such as Pebble and FormLab 3D Printer have been transformed from conceptual designs to actual products. Other projects have become fledgling businesses with great profit potential (Schroter, 2014).

\section{6}

\subsection{Backers of online crowdfunding}

The previous section presented a brief history on the development of crowdfunding and made a case for how crowdfunding today is different than the earlier, more primitive forms from which it evolved. Through Internet technologies, modern crowdfunding allows entrepreneurs to enlist a more widely dispersed, heterogeneous and less identifiable crowd (Lehner et al., 2015). Even though backers provide financial support to crowdfunding projects as venture capitalists (VCs) or angel investors do, several key features differentiate backers from traditional investors. For instance, VCs or angel investors adopt profit returns as the primary criteria to decide whether to invest in a project (Cardon et al., 2009), while backers on a crowdfunding site such as Kickstarter donate money to a crowdfunding project without receiving any return (Kshetri, 2015; Meer, 2014). VCs or angel investors hold equities without participating in product design or manufacturing process (Cardon et al., 2009), while backers hold no equity and actively engage in the crowdsourcing activities during the fundraising period (Schwienbacher and Larralde, 2010). These differences clearly affect motivations. Thus, an in-depth understanding of backers and their motivations can help academics and practitioners to advance knowledge of how to successfully reach the funding goal. In this study, to highlight these features and in keeping with terminology used in prior studies and industry, the term "backers" was adopted to represent the "crowd" backing crowdfunded projects.

Backers contribute several critical benefits to innovative crowdfunding projects. Research in the general field of innovation has associated external partnerships with increased innovation (Tether, 2002; de Faria et al., 2010; Zeng et al., 2010). Backers enable peer-to-peer collaboration early on in the development of costly and risky innovation projects. This collaboration helps identify problems and mistakes early, thus reducing cost and risk. Indeed, Eric Reis's (2011) Lean Startup methodology advocates early testing in the external environment to enable quick correction and validation. According to Reis, this saves waste in terms of time, effort and money and is important for any innovative project. For backers, crowdfunding enables them to get involved in investment activities, including the decision of what does and does not get funded, that were previously in the exclusive realm of institutional investors. For entrepreneurs, crowdfunding allows them to raise funds without going through traditional institutional financial intermediaries (gatekeepers) such as investment banks (Lin et al., 2013). This ability to appeal directly to the crowd for funding is especially important considering that institutional financial intermediaries are especially focused on minimizing risk and, often by default, innovation. Crowdfunding projects are inherently focused on innovation and uniqueness making it difficult to make comparative risk assessments, thereby making them naturally risky. Traditional investors are risk averse, which can make them leery of untried innovative products, whereas the crowd loves innovation. These dichotomous viewpoints essentially mean that all traditional factors known to be associated with the decision to back a project cannot be applied to the crowd that has different values and goals. It also means that peer-to-peer crowdfunding enriches the funding sources for the transformation and commercialization of products, innovative projects in particular.

Secondly, crowdfunding is an engaging crowdsourcing process. Crowdsourcing refers to a process in which companies obtain ideas, suggestions and feedback from backers before 
making the products (Bayus, 2013). With the early engagement of backers who are possible future customers, companies are able to precisely learn the market needs and offer the right products to customers. Even though the terminologies are slightly different, Schwienbacher and Larralde (2010) argue that crowdfunding is actually a combination of funding and crowdsourcing. During a project's fundraising process, backers not only offer financial support to the project, but also give constructive feedback and suggestions to the project. Subsequently, the project owners can use this "crowd intelligence" to continually improve project design and quality during the funding process.

Third, crowdfunding unintentionally creates an informal watchdog group that monitors the entrepreneur's funding usage and project implementation. Even though the pledged funds from backers have some characteristics of charitable donations, the involvement of social media into the fundraising process empowers backers to share postfunding information with other backers. This key feature motivates the entrepreneur(s) to complete the project on time and on budget as promised during the fundraising process, in order to "snowball" their good reputation via crowdfunding websites and social media. Thus, backers push crowdfunding to grow in positive directions.

\subsection{Crowd motivations}

Most research to date has focused on the successful use of crowdfunding by the entrepreneur or project owner, specifically success factors (Lehner et al., 2015; Mollick, 2014). Relatively little is known about what motivates backers (Bretschneider and Leimeister, 2017; Cholakova and Clarysse, 2015; Colombo et al., 2015). From this viewpoint the crowd, composed of potential project backers, has received attention primarily as an obscure and inanimate success factor; something to be attracted and appealed to. However, backers are neither stationary devices that do the same thing every time, employees to be managed, nor buyers to be marketed to. Instead, backers are participatory individuals who play an active and central role.

Traditional investors are motivated by potential profits, which they weigh against risk. They tend to be risk averse, which can make them leery of untried innovative products. On the other hand, the crowd typically has no potential for profits and loves innovation. This means traditional understandings of investor motivations cannot be directly applied to understand the motivations of crowdfunding backers. Likewise, our understanding of customer motivations does not necessarily apply to crowdfunding backers who are not purchasing anything and therefore not motivated in the common way by price, cost and value.

Recently researchers have focused on identifying crowdfunding success factors, which indirectly measure backer motivations since motivated backers are the ones who make the decision to support projects, which in turn makes a project successful. A more direct window into backer motivations is possible by looking at what backers say. This can be found in the comments backers make. KickStarter and most other crowdfunding portals backers have a comment section where comments about particular projects can be posted.

\subsection{Project comments}

The comments feature of online crowdfunding platforms helps the crowd interact with each other and project owners as they evaluate the worthiness of projects. Comments allow potential backers to collaborate in this evaluation, with the end result being a decision to support or not support a crowdfunding project. In the same way that it has become critical for marketers to understand the power of online reviews and their influence on consumer behavior (Zhang et al., 2014), so too is it critical for crowdfunding project owners to 
EJIM

25,6

228

understand the power and influence of backer and project owner comments on a backer's decision to support a project.

Project owners generate and provide all of the primary information available to the crowd regarding the project, making it particularly vital for project owners to understand backer motivations. However, project owner-generated content is only half the picture and almost immediately backers begin generating additional project information in the form of comments. Backers interact with each other and project owners via online comments that influence backer decisions. Also, potential backers may decide not to back a product based on other backer comments or interactions between backers and project owners. All crowdfunding websites offer the crowd an online comments function. Comments give the crowd a voice, allowing them to raise questions, offer feedback and show their opinions about projects. Technical and marketing help can be found in these comments by entrepreneurs savvy enough to look, but they also provide a great opportunity to adopt text mining techniques to "read" the crowd's mind and investigate the latent factors that influence the crowd's funding decisions.

\subsection{Theory}

Theories such as the technology acceptance model (TAM) are often used in the information systems (IS) literature to measure success factors, which include ease of use (EU) and perceived usefulness (PU). Much of the research on crowdfunding centers on these types of success factors, which focus on tangible and easily measurable factors related to the benefits of backing a project. Benefits related to higher-level needs such as innovation, communication, collaboration and decision-making are not captured by EU and PU scales (Sun and Teng, 2017).

Exploratory studies do not test or develop theory, but can still use theory in a broad manner to guide the study (Franklin, 2005). With a research question focused on backer motivations, a general theory of motivations was needed to guide this study. Maslow's hierarchy of needs, composed of five levels, is one such theory (Maslow, 1943). A shortcoming of Maslow's theory is that it is a broad theory of human development and not focused on work motivation (Landy, 1989). Alderfer's 1972 ERG (existence, relatedness, growth) theory addressed several shortcomings of Maslow's theory and is focused on work motivations rather than more general needs (Arnolds and Boshoff, 2002).

ERG theory (Alderfer, 1972) was developed from Maslow's hierarchy of needs, originally to investigate employee motivations. ERG has previously been used to evaluate web interface design with a focus on motivational issues, the premise being that an appealing website is like a motivational workplace (Zhang et al., 1999). ERG is used for investigating motivations by grouping motivating needs into three broad categories: existence, relatedness and growth. According to Alderfer's 1972 ERG theory, people are motivated by three groups of core needs: existence, growth and relatedness.

Of these three needs, only relatedness needs focus specifically on the social relational needs. These needs include things such as social acceptance, belongingness and status desires. Crowdfunding platforms seek to introduce projects to the crowd, with the goal of relating to the crowd in such a way that the crowd provides support, especially financial support. In his 1972 book, Alderfer admits that satisfaction of social motives did not seem to be related to a desire for material things. Some perceive this as a weakness in the theory; that the theory focuses on more intangible social needs to the neglect of material needs such as the purchase of goods (Mausner, 1972). However, these intangible social needs are likely what motivate backers who purchase nothing and receive no ownership in the projects they support.

In this study, we turn to Homans' (1961) SET to help interpret relatedness motivational findings in a social context. SET offers more insight on social relational needs than ERG. SET 
is most often used to examine social relationships such as those found in marriage relationships, which are not governed by ownership or exchange of goods. However, SET has also been used to look at business relationships in IS research, and a general model of SET from St. John et al. (2014) can be found in Figure 1.

SET posits that the dependent variable relationship success, in this case a successfully funded project, is affected by independent variables including trust, communication and interdependence. These factors are of special interest in understanding what might motivate the crowd to pledge funds to an entrepreneurial project.

Entrepreneurial crowdfunding backer motivations

\section{Methodology}

One problem with measuring backer motivations is that backers, as members of the anonymous and physically dispersed virtual crowd, are difficult to observe or even survey. Furthermore, the individuals comprising a project's crowd change temporally, and the individuals comprising each project's crowd are much different from those of other project crowds. All this makes surveying, directly measuring and even simply identifying the individuals of the crowd difficult. A further problem is that human emotions and motivations are complex and occur partially or even wholly at the subconscious level. Actions are motivated by a combination of many factors and often taken automatically at a subconscious level without going through a conscious, structured checklist. Backers are unlikely to be able to verbalize more than the primary conscious-level factors. For these reasons, survey methods, though valuable, are limited because they rely on a conscious recollection of past motivations.

\subsection{Text analysis}

The primary task in analyzing text is coding it. Coding involves differentiating and combining the data into categories so its essential meaning can be captured (Miles and Huberman, 1994). Traditionally this is done manually (Berg and Lune, 2011). One problem with manual coding is its cost and inability to analyze large data sets. Another problem is subjectivity from human involvement, which raises threats to validity and reliability (Debortoli et al., 2016; Urquhart, 2001).

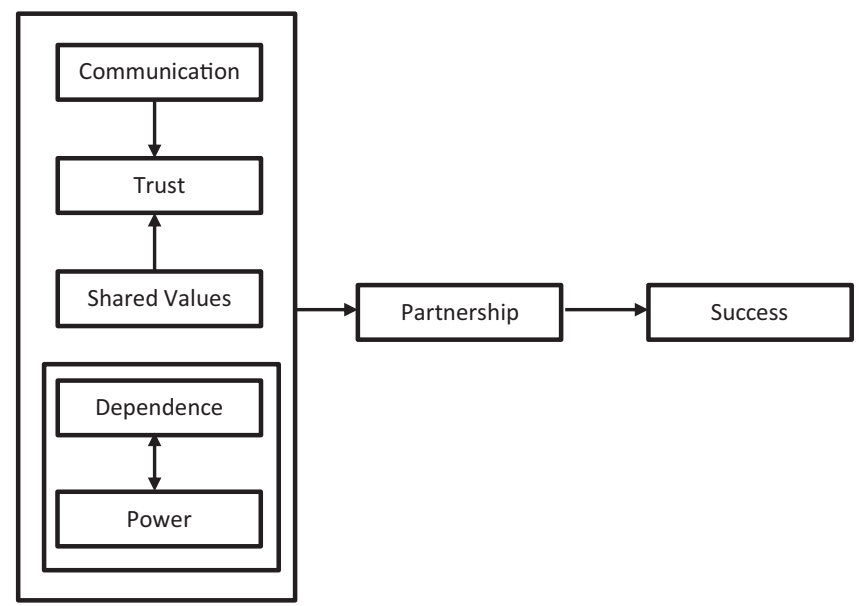

Figure 1. 
EJIM

25,6

Automated text analysis is a machine learning technique that allows researchers to analyze large sets of unstructured data in ways not possible with traditional analysis or manual text analysis. Automated text analysis allows for the automatic extraction of previously unknown, implicit knowledge from large amounts of unstructured textual data (Fan et al., 2006). With sufficiently large data sets, it is considered a reliable tool (Halevy et al., 2009). Debortoli et al. (2016) recommend it for IS researchers to "1) overcome the limitations of manually analyzing qualitative data and 2) yield insights that they could not otherwise find." Unlike manual techniques, machine learning is very cost-effective. Although interpretation of the analysis relies on the human element, algorithms used in analysis are purely objective, which improves validity and reliability. Recently, the use of machine learning algorithms in research has seen a dramatic increase while in business these automated text mining techniques for finding and applying patterns in unstructured data "pretty much run the world" (Hao, 2018, p. 1).

The various coding techniques, both manual and automated, can be classified as either bottom-up or top-down approaches. With a top-down approach, the researcher decides the topics of interest a priori, usually based on the literature or a theory being tested. Numerous supervised machine learning algorithms exist for automating text analysis using a top-down approach. With a bottom-up approach, the data is allowed to suggest the codes (i.e. words) regardless of theory (Debortoli et al., 2016; Urquhart, 2001).

\subsection{Topic models}

Referred to as topic models, unsupervised machine learning algorithms use a bottom-up approach to automatically find relationships between word use and its category assignment. The advantage of a bottom-up approach is that it avoids imposing preconceptions on the data and allows for the discovery of latent factors (Debortoli et al., 2016).

Topic models are naturally descriptive because they are quantitative summaries of large data sets. However, one can use existing theories and literature to do more than just describe a particular corpus. As suggested by Debortoli et al. (2016), one can map automatically identified topics with theoretical constructs and fit them to a theoretical model. In this paper, LDA was used to discern topics that were then fit into a subsequent explanatory model of SET (Figure 1). A total of 42,956 words were collected from KickStarter.com's 100 most successfully funded technology projects in 2015. Collection was restricted to the most successful projects because those projects were the ones where backer motivations were the highest, as measured by funding. Those comments, made by backers during the time the decision to support or not support was made, were analyzed in an attempt to discover latent factors hidden in the backer's comments. Those latent factors were then fit to a theoretical model based on SET.

The methodology design was twofold: First, backer comments were collected. Secondly, because of the exploratory nature of this study and because of the requirements of the data analysis used, an expert panel was used to guide the analysis and determine the number of factors to model.

\subsection{Comments data}

Online comments on a crowdfunding site are similar to online customer reviews in online marketplaces. Both are word-of-mouth (WOM) forms of communication, which have been identified as one of the most important methods of communication between consumers, especially in the online environment (Ullah et al., 2016). They have also been identified as challenging to analyze because of the volume and variety of content, which is textual and unstructured (Salehan and Kim, 2016). Since the backer comments data was obtained from successfully funded projects, the data set contained the hidden variables that can motivate the majority of backers to pledge funds to projects. A text mining methodology was 
appropriate for investigating the "crowd intelligence" regarding the backers' motivations. The following methodology was adopted to investigate the crowdfunding decision fit between backers and entrepreneurs: On the backer side, an LDA analysis strategy proposed by Blei et al. (2003) was adopted to investigate the factors that can motivate the backer's decision to support a project. According to Mollick (2014), backers are "extremely heterogeneous" and their motivations complex. It would be very difficult to survey the anonymous and globally scattered backers about what convinced them to give funds to the crowdfunding projects. However, the backer's online comments provide a wealth of information that can reveal the latent factors that convinced them to support crowdfunding projects. In fact, motivations can be revealed, which backers themselves may not consciously be aware of or be able to verbalize, especially at a later point in time when responding to a survey. Comments from each of KickStarter.com's 100 most funded technology projects were treated as separate "documents" for their similar themes. This surpassed the "sufficiently large" data set $(n>1,000)$ for producing valid results in topic modeling (Debortoli et al., 2016). By analyzing comments across these 100 documents, the "crowd opinions" that influenced other backers' opinion of the crowdfunding project were obtained regardless of the type of artifact. A total of 42,956 words were collected from these projects. A more detailed discussion of the text mining process using LDA is given in the "Data Analyses" section below.

\subsection{Data Analyses}

LDA uses an unsupervised machine learning approach to topic modeling. LDA is a newgeneration mixed-membership model. It breaks the limitations of classical mixture models, which assumes each document only exhibits one topic, and is able to detect the common latent factors across documents in a corpus. Thus, it is a helpful model for exploring the common factors that exist among successful technology crowdfunding projects regardless of what products are proposed in the projects.

3.4.1 Expert panel. As noted by Debortoli, "text mining requires the skill sets of a diverse set of fields, including computer science and linguistics, and not every IS researcher is familiar with these field's concepts and methods" (2016, p. 112). Not all text analysis requires subject matter expertise for interpretability. For instance, identifying trends, patterns or documents with inappropriate words does not require expertise. However, substantive interpretability is a crucial requirement for studies involving culture, including motivations (DiMaggio et al., 2013).

In regard to topic-construct mapping, Debortoli recommends that multiple researchers with both domain and theoretical knowledge be involved in identifying topics and fitting them in their nomological network. An expert panel comprising three entrepreneurs, including two of the authors, who successfully raised funds from KickStarter was asked to share what they believe are the critical factors (topics) that influence a backer's decision to support a project. All three experts had extensive prior experience as both traditional "brick and mortar" business owners and web-based, small business owners. The three experts had successfully raised over $\$ 10,000$ in funds through a 2012 KickStarter campaign with an initial goal of $\$ 4,000$. As of December 11,2020, the majority of Kickstarter projects are unsuccessful. Of those that do succeed, only $33.19 \%$ garnered $\$ 10,000$ or more, according to KickStarter statistics. Having expert practitioners identify the number of topics was important since the methodology used does not make this determination. The expert panel identified ten topics. This fits with Debortoli's suggestion that for topic models that humans can interpret a low number of topics (e.g. between 10 and 50) be chosen (2016). So, subject matter expertise is needed for choosing the number of topics and then again for ensuring interpretability.

LDA believes that topics (i.e. hidden variables or latent factors being investigated) are distributions over terms (i.e. the observable words contained in the documents). In addition, 
EJIM

25,6

232

LDA assumes that each document has a particular distribution over topics. Although topics are not observable directly, one can use a "reversed" probabilistic generative analysis to estimate these hidden variables according to the observable terms in the documents. The LDA's probabilistic generative analysis is shown below:

Suppose $K$ topics are being investigated from a corpus with a size $V$. The corpus is constructed by $D$ documents with various $N$ terms in each document. For each topic, draw a distribution over terms $\vec{\beta}_{k}$, and $\vec{\beta}_{k}$ follows $\operatorname{Dir}_{V}(\eta)$, where $\operatorname{Dir}_{V}(\eta)$ denotes a $K$ dimensional symmetric Dirichlet distribution with the scalar parameter $\eta$. For each document, draw a vector of topic proportions $\vec{\theta}_{d}$, and $\vec{\theta}_{d}$ follows $\operatorname{Dir}(\vec{\alpha})$, where $d \in D$ and $\operatorname{Dir}(\vec{\alpha})$ denotes a $V$-dimensional Dirichlet distribution with vector parameter $\vec{\alpha}$. For each word, draw a topic assignment $Z_{d, n}$, and $Z_{d, n}$ follows $\operatorname{Mult}\left(\vec{\theta}_{d}\right)$, where $\operatorname{Mult}\left(\vec{\theta}_{d}\right)$ denotes a multinomial distribution with vector parameter $\vec{\theta}_{d}$, and $Z_{d, n} \in\{1, \ldots, K\}$. Then draw a word $W_{d, n}$, and $W_{d, n}$ follows Mult $\left(\vec{\beta}_{Z_{d, n}}\right)$, where $\operatorname{Mult}\left(\vec{\beta}_{Z_{d, n}}\right)$ denotes a multinomial distribution with vector parameter $\vec{\beta}_{Z_{d, n}}$, and $W_{d, n} \in\{1, \ldots, V\}$. The reversal of this generative process leads to the following posterior distribution of the hidden variables given the $D$ observed documents $\vec{w}_{1: D}$,

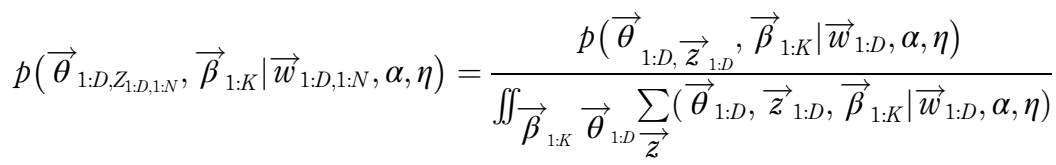

As shown in equation (1), this posterior distribution is calculated to estimate the possible topics according to the probability of terms grouped under each topic. The posterior distribution calculation was implemented in the software $R$. The data analysis process consisted of two steps, including data preprocessing and LDA.

\subsection{Data preprocessing}

The purpose of the data preprocessing was to eliminate the "noise" data from the corpus. Punctuations, whitespaces and stop words (e.g. "a," "an," "the," etc.) were removed. The minimum word length considered was set to 3 , so that frequently appearing but meaningless words (e.g. "me," "one," "yes," etc.) could be removed from the data set. After this step, the result was a data set consisting of 100 documents with 42,956 words. As suggested by the term-frequency inverse document frequency (tf-idf) scores were calculated in order to find the cutoff point for vocabulary selection. The tf-idf scores are listed in Table 1. As suggested by Grün and Hornik (2011), we adopt 2.50 as the cutoff tf-idf score. Finally, a corpus consisting of 46 documents that had 18,924 words was received.

\section{Results and discussion of select backer motivational factors} 4.1 Results

The labeling and interpretation of topics extracted by LDA are left to the researcher (Schouten and Frasincar, 2016). Asmussen and Moller (2019) point out that the labeling of topics is highly subjective. They suggest a combination of reviewing the most frequent words

Table 1.

\begin{tabular}{lccccc}
\hline Min & 1 st Qu & Median & Mean & 3rd Qu & Max \\
\hline $4.635 \mathrm{e}-05$ & $1.104 \mathrm{e}-04$ & $2.152 \mathrm{e}-04$ & $5.963 \mathrm{e}-04$ & $4.615 \mathrm{e}-04$ & $2.195 \mathrm{e}-01$
\end{tabular}


for each topic and a title review to lower the risk of incorrectly labeling topics. LDA does not expect all or even most factors to be interpretable so focus was placed on those that were interpretable with the help of, and in the context of, SET. Table 2 shows the 10-topic LDA analyses and the five topics that the experts labeled and mapped to the known theoretical constructs of SET.

LDA was used to discern topics that were then labeled by the expert panel. Those labels were then mapped to the known theoretical constructs of SET. This mapping is shown in Figure 2.

\subsection{Project updates}

Project updates are similar to comments, but they are one-way communications posted only by the project owner to announce such things as project progress, changes or important project milestones. As a clear form of communication, we fit updates with communication in SET. In his study on crowdsourcing, Organisciak (2010) found that asking users a question that they can answer was itself a big motivator. An example is Wikipedia, where volunteers are motivated to build content simply because they have knowledge they can share.

As Organisciak (2010) previously discovered in his investigation of crowdsourcing projects including Wikipedia, people are motivated to help and provide advice especially when they feel they know the answer. Boutillier (2019) identified the "wisdom of crowds" as an important source of benefits including knowledge for innovative projects. LDA topic \#3 had the key words "know" and "update," which offer strong support that backers of crowdfunding are also motivated to help and share knowledge they may have. Other keywords in topic 3 are common subjects of updates.

\subsection{Trust}

SET views any human interaction as one involving an exchange of both tangible and intangible benefits (Homans, 1961). Often, the intangible benefits are the most important ones, and that is likely the case in the crowdfunding exchange where the backer receives no ownership and little physical reward beyond perhaps a minor reward. SET holds that trust is a major factor in the success of any relationship.

On closer examination of the results, distinct types of uses are important factors for backers. In LDA topic 2, the word "use" is associated with words such as "charge," "receive," "ship," "work" and "track." According to Cappa et al. (2020), trust that the project owner(s) will meet their goals and ship rewards affects backers' trust that they will receive those rewards and therefore their willingness to pledge funds. Based on these associated keywords, "use" in LDA topic 2 does not relate to how the product will be used but rather whether or not it will be

\begin{tabular}{lcl}
\hline Label & Topic & Words \\
\hline Value & 1 & Embrace, refund, project, survey, money, update \\
Trust & 2 & Use, charge, receive, ship, work, track \\
Project updates & 3 & Project, pledge, ship, backer, update, know \\
& 4 & Use, control, work, support, play, connect \\
Altruism & 5 & Plant, kit, seed, work, pledge, goal \\
& 6 & Love, help, book, kid, show, think \\
Psychological ownership & 7 & Device, plug, use, file, drive, geek \\
& 8 & Use, support, team, work, device, look \\
& 9 & Ship, work, product, light, app, android \\
& 10 & Use, printer, print, software, machine, model
\end{tabular}

Entrepreneurial crowdfunding backer motivations

233 


\section{EJIM \\ 25,6}

\section{4}

Figure 2.

Latent backer

motivations

framework

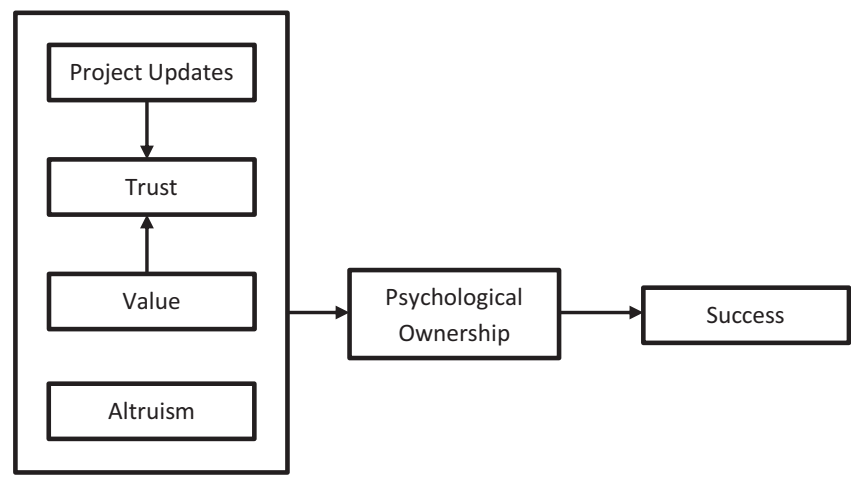

produced and be delivered so that it can be used. Products have reduced or no usability when they do not "work," "ship" late or are never "received" at all. A study by CNNMoney of KickStarter's top 50 most-funded projects found that only $16 \%$ shipped on time (Cowley et al., 2012). Mollick (2014) examined 471 successful products in the design and technology categories and found that only $24.9 \%$ of projects shipped on time. Design and technology are the same categories that were examined in the current study. KickStarter has enjoyed continued dramatic growth despite the well-documented failures in shipping. Rather than indicating apathy on the subject, our findings suggest that backers are concerned with shipping, tracking and being charged for products that are not shipped. Trust is important.

\subsection{Value}

KickStarter is a rewards-based crowdfunding platform where projects offer backers rewards. Rewards can be as simple as a thank you card or a t-shirt, but for projects attempting to create a product, rewards are usually promises to ship samples of the product. However, the panel of experts agreed that value constituted far more than value intrinsic to the rewards.

LDA topic 1 contains the keywords "money" and "refund" and directly relates to the monetary aspects of value while the additional keywords "project," "survey" and "update" could show an interest in discovering the value of the project. Support for the importance of value has been demonstrated in the crowdfunding of journalism projects. Backers show a preference for backing projects they find useful (Jian and Usher, 2013; Pietro et al., 2021). A simple definition of value is benefit minus cost, which results in positive or negative value. Backers are more likely to "embrace" a project after consciously or subconsciously making this simple calculation and determining the project's value.

\subsection{Altruism}

The expert panel agreed that one almost intangible, yet very important factor they identified was "Altruism." Jian and Shin (2015) identified altruism as an important factor in crowdfunded journalism. Journalism is a different category than the design and technology category investigated in this study. Moritz and Block (2014) found that social and nonprofitoriented projects have a higher probability of receiving crowdfunding. This higher likelihood of funding seems in large part attributable to altruism. The expert panel still felt altruism plays an important role in for-profit projects and that those projects are also evaluated by backers on whether they are for a good cause, the right thing to do or had moral justifications. People like to help if they believe in the project (Organisciak, 2010). This helps them relate, and relatedness is the ERG theory factor this study is guided by. Furthermore, backers seem 
to have a desire to tout the goodness of a cause (or lack thereof) in their comments. Projects that involve improving or innovating products or services have that altruistic factor, more or less, depending on how the project is presented.

LDA topic 6 groups keywords "help," "show," "think," "kid" and "love." Kids, love, showing and helping are not normally associated with traditional funding. Traditionally, bank loan officers do not evaluate business plans on these terms. Crowdfunding backers, on the other hand, have different motivations. They are getting a benefit, in the form of good feelings from backing a project. Backers are getting a benefit from being altruistic that is not readily discernible from a balance sheet point of view. Neurobiologists have found that altruism is part of human nature and makes us feel good (Winerman, 2005).

\subsection{Psychological ownership}

One type of value, nonintrinsic value gained by being a part of and therefore "owning" part of the project, was deemed important enough to be considered a separate factor, which they identified as "psychological ownership." Gerber et al. (2012) identified active participation in projects by backers as enabling them to enjoy the sense of belonging to a crowdfunding community. Belleflamme et al. (2014) referred to the "community benefit" enjoyed by backers. Colistra and Duvall (2017) noted that backers typically feel like they are actively involved in the projects they support. In their investigation into crowdfunding cocreation between project owners and backers, Lipusch et al. (2020) recognized the importance of backer's feelings of psychological ownership. We use the term psychological ownership because in their experience, the expert panel found that it was more than just a sense of belonging or participation.

In contrast to traditional investors, backers of crowdfunding projects do not gain shares or legal ownership in the project. However, backers feel a very strong connection and feel ownership because they know that they played a vital role in making the project happen. This was a surprising finding by all three project owners and was in stark contrast to their prior experiences as small business owners and sellers on eBay. This feeling of ownership by backers was expressed not only in the form of valuable monetary support but also as valuable advice freely given through comments. Backers offered design change suggestions, suggested additional rewards and even offered advice on bringing the product to market post KickStarter.

The panel of experts felt that it was important for backers to have psychological ownership. Not legal or monetary ownership, but rather social ownership or at least a feeling of being an important part of the project. For an entrepreneur lacking the resources and expertise normally available to large companies, external help from project partners and outside partners such as manufacturers and the crowd can be vital for success. The crowd knows this and wants this to be acknowledged by the project owner(s). This social reciprocity is an important factor for motivating backers.

In LDA topic 8, words wuch as "support" and "team" relate to psychological ownership. The panel of experts pointed out that when their own project passed funding goals or had other successes, backers would proudly point successes out with their comments and use the term "we" as in "look what we did!" The term "Support" from backers for the "device" being developed or "work" being done was vital for the success of the project. According to the panel of experts, psychological ownership with backers has a beneficial networking result. Backers who feel a sense of psychological ownership help to spread the word and can aid the project in going viral. Backers consider themselves to be participatory decision-makers and want to be a part of the project. Project owners who view backers as passive customers miss out on the shared support from the crowd. Without any actual ownership in the project, one would not expect that psychological ownership would exist as a motivating factor. However, 
EJIM

25,6

research on organizational commitment has found similar motivations among employees. Specifically, Meyer and Allen (1991) found that employees who WANT to belong to an organization are far more committed than employees who NEED to belong or employees who are OBLIGATED to belong. So, counterintuitive backers who do not own shares or have legal ownership seem to be more committed and feel more ownership in the project.

4.7 Success

Success in crowdfunding depends on obtaining funds by convincing a large number of people, the crowd, to support a project (Adamska-Mieruszewska et al., 2021). In this study success was controlled by restricting data collection to a grouping of the most successful projects.

\section{Conclusion}

In recent years, organizations have been discovering valuable new information hidden in the subtle patterns and texture of large quantities of unstructured textual data. The extraction, coding and analysis of large corpus of data is a new and emerging field of research. One limitation of this study is that we examined backer motivations in reward-based crowdfunding. One would expect motivations to differ for backers in donation-based crowdfunding who receive no rewards or for backers of equity-based crowdfunding who receive equity in the project.

The unique contributions of this study are twofold. First, by analyzing backer comments from a set of only the most successful campaigns, we captured motivational factors that occurred at the time backers were motivated to support a project. LDA allows for the capture of latent factors. This descriptive view of hidden factors gives insight on both conscious and unconscious motivations and provides researchers with a different view of the data on backer motivations. Of special interest is support found for the latent factor psychological ownership, which differs from the traditional, explicit, financial definition of ownership. Given strong feelings of psychological ownership, project owners should actively engage the crowd and solicit the crowd for advice and help in order to motivate them.

Secondly, this study goes beyond description by its examination of latent factors using the lens of SET. By mapping automatically identified topics with theoretical constructs and fitting them to a theoretical model, a framework is provided for future investigations of backer motivations.

Online chatter in the form of user-generated comments is an excellent data source for researchers to mine for value and meaning. In this study, that meaning consisted of extracting the key latent factors that motivate backers to support a project. An understanding of what motivates these new networks of financial decision-makers collectively referred to as the "crowd" or "backers" is of fundamental value for entrepreneurs seeking their support.

\section{References}

Adamska-Mieruszewska, J., Mrzygłód, U., Suchanek, M. and Fornalska-Skurczyńska, A. (2021), "Keep it simple. The impact of language on crowdfunding success", Economics and Sociology, Vol. 14 No. 1, pp. 130-144, doi: 10.14254/2071-789x.2021/14-1/9.

Alderfer, C.P. (1972), Existence, Relatedness, and Growth: Human Needs in Organizational Settings, Free Press, New York.

Allison, T.H., Davis, B.C., Webb, J.W. and Short, J.C. (2017), "Persuasion in crowdfunding: an elaboration likelihood model of crowdfunding performance", Journal of Business Venturing, Vol. 32 No. 6, pp. 707-725, doi: 10.1016/j.jbusvent.2017.09.002. 
Arnolds, C.A. and Boshoff, C. (2002), "Compensation, esteem valence and job performance: an empirical assessment of Alderfer's ERG theory", The International Journal of Human Resource Management, Vol. 13 No. 4, pp. 697-719, doi: 10.1080/09585190210125868.

Asmussen, C.B. and Møller, C. (2019), "Smart literature review: a practical topic modelling approach to exploratory literature review", Journal of Big Data, Vol. 6 No. 1, doi: 10.1186/s40537-019-0255-7.

Entrepreneurial crowdfunding backer motivations

Barnett, C. (2013), Donation-Based Crowdfunding Sites: Kickstarter vs Indiegogo, Forbes, Forbes Magazine, 9 September, available at: https:/www.forbes.com/sites/chancebarnett/2013/09/09/ donation-based-crowdfunding-sites-kickstarter-vs-indiegogo/(accessed 28 December 2020).

Bayus, B.L. (2013), "Crowdsourcing new product ideas over time: an analysis of the dell IdeaStorm community", Management Science, Vol. 59 No. 1, pp. 226-244, doi: 10.1287/mnsc.1120.1599.

Belleflamme, P., Lambert, T. and Schwienbacher, A. (2014), "Crowdfunding: tapping the right crowd", Journal of Business Venturing, Vol. 29 No. 5, pp. 585-609, doi: 10.1016/j.jbusvent.2013.07.003.

Berg, B. and Lune, H. (2011), Qualitative Research Methods for the Social Sciences, Pearson, New York City, NY.

Blei, D., Ng, A., Jordan, M. and Lafferty, J. (2003), "Latent dirichlet allocation”, Journal of Machine Learning Research, Vol. 3 Nos 4/5, pp. 993-1022.

Boutillier, S. (2019), "The economics of the entrepreneur and the banker historical roots and contributions to the management of innovation", European Journal of Innovation Management, Vol. 23 No. 2, pp. 230-250, doi: 10.1108/ejim-08-2018-0184.

Brem, A., Bilgram, V. and Marchuk, A. (2019), "How crowdfunding platforms change the nature of user innovation - from problem solving to entrepreneurship", Technological Forecasting and Social Change, Vol. 144, pp. 348-360, doi: 10.1016/j.techfore.2017.11.020.

Bretschneider, U. and Leimeister, J.M. (2017), "Not just an ego-trip: exploring backers' motivation for funding in incentive-based crowdfunding", The Journal of Strategic Information Systems, Vol. 26 No. 4, pp. 246-260, doi: 10.1016/j.jsis.2017.02.002.

Bretschneider, U., Knaub, K. and Wieck, E. (2014), Motivations for Crowdfunding: What Drives the Crowd to Invest in Start-UPS?, ECIS, Tel Aviv.

Burger-Helmchen, T., Laperche, B., Schiavone, F. and Stefani, U. (2020), "Financing novelty: new tools and practices to induce and control innovation processes", European Journal of Innovation Management, Vol. 23 No. 2, pp. 197-199, doi: 10.1108/ejim-03-2020-333.

Burtch, G., Ghose, A. and Wattal, S. (2013), "An empirical examination of the antecedents and consequences of contribution patterns in crowd-funded markets", Information Systems Research, Vol. 24 No. 3, pp. 499-519, doi: 10.1287/isre.1120.0468.

Busse, M. and Siebert, R. (2018), "The role of consumers in food innovation processes", European Journal of Innovation Management, Vol. 21 No. 1, pp. 20-43, doi: 10.1108/ejim-03-2017-0023.

Cappa, F., Pinelli, M., Maiolini, R. and Leone, M.I. (2020), "Pledge' me your ears! the role of narratives and narrator experience in explaining crowdfunding success", Small Business Economics. doi: 10.1007/s11187-020-00334-y.

Cardon, M., Sudek, R. and Mitteness, C. (2009), "The impact of perceived entrepreneurial passion on angel investing", Frontiers of Entrepreneurship Research, Vol. 29 No. 2, pp. 1-15.

Cholakova, M. and Clarysse, B. (2015), "Does the possibility to make equity investments in crowdfunding projects crowd out reward-based investments?", Entrepreneurship Theory and Practice, Vol. 39 No. 1, pp. 145-172, doi: 10.1111/etap.12139.

Colistra, R. and Duvall, K. (2017), "Show me the money: importance of crowdfunding factors on backers' decisions to financially support kickstarter campaigns", Social Media + Society, Vol. 3 No. 4, 205630511773694, doi: 10.1177/2056305117736942.

Colombo, M.G., Franzoni, C. and Rossi-Lamastra, C. (2015), "Internal social capital and the attraction of early contributions in crowdfunding", Entrepreneurship Theory and Practice, Vol. 39 No. 1, pp. 75-100, doi: 10.1111/etap.12118. 
EJIM

25,6

Courtney, C., Dutta, S. and Li, Y. (2016), "Resolving information asymmetry: signaling, endorsement, and crowdfunding success", Entrepreneurship Theory and Practice, Vol. 41 No. 2, pp. 265-290, doi: 10.1111/etap.12267.

Cowley, S., Goldman, D., Pepitone, J., Segall, L. and Smith, O. (2012), Kickstarter's Top Projects: When They Shipped, CNNMoney, Cable News Network, available at: https://money.cnn.com/2012/12/ 18/technology/innovation/kickstarter-ship-delay/index.html (accessed 28 December 2020).

De Crescenzo, V., Ribeiro-Soriano, D.E. and Covin, J.G. (2020), "Exploring the viability of equity crowdfunding as a fundraising instrument: a configurational analysis of contingency factors that lead to crowdfunding success and failure", Journal of Business Research, Vol. 115, pp. 348-356, doi: 10.1016/j.jbusres.2019.09.051.

de Faria, P., Lima, F. and Santos, R. (2010), "Cooperation in innovation activities: the importance of partners”, Research Policy, Vol. 39 No. 8, pp. 1082-1092, doi: 10.1016/j.respol.2010.05.003.

Debortoli, S., Müller, O., Junglas, I. and vom Brocke, J. (2016), "Text mining for information systems researchers: an annotated topic modeling tutorial", Communications of the Association for Information Systems, Vol. 39, pp. 110-135, doi: 10.17705/1cais.03907.

DiMaggio, P., Nag, M. and Blei, D. (2013), "Exploiting affinities between topic modeling and the sociological perspective on culture: application to newspaper coverage of US government arts funding", Poetics, Vol. 41 No. 6, pp. 570-606, doi: 10.1016/j.poetic.2013.08.004.

Fan, W., Wallace, L., Rich, S. and Zhang, Z. (2006), "Tapping the power of text mining", Communications of the ACM, Vol. 49 No. 9, pp. 76-82, doi: 10.1145/1151030.1151032.

Franklin, L.R. (2005), "Exploratory experiments", Philosophy of Science, Vol. 72 No. 5, pp. 888-899, doi: $10.1086 / 508117$.

Frydrych, D., Bock, A.J., Kinder, T. and Koeck, B. (2014), "Exploring entrepreneurial legitimacy in reward-based crowdfunding”, Venture Capital, Vol. 16 No. 3, pp. 247-269, doi: 10.1080/13691066. 2014.916512.

Gerber, E.M. and Hui, J. (2013), "Crowdfunding”, ACM Transactions on Computer-Human Interaction, Vol. 20 No. 6, pp. 1-32, doi: 10.1145/2530540.

Gerber, E., Hui, J. and Kuo, P. (2012), "Crowdfunding: why people are motivated to post and fund projects on crowdfunding platforms", Proceedings of the ACM 2012 Conference on Computer Supported Cooperative Work and Companion CSCW '12: Seattle, Washington, USA, February 11-15, 2012, Vol. 10.

Grün, B. and Hornik, K. (2011), “Topic models: an R package for fitting topic models”, Journal of Statistical Software, Vol. 40 No. 13, doi: 10.18637/jss.v040.i13.

Halevy, A., Norvig, P. and Pereira, F. (2009), "The unreasonable effectiveness of data”, IEEE Intelligent Systems, Vol. 24 No. 2, pp. 8-12, doi: 10.1109/mis.2009.36.

Hao, K. (2018), What Is Machine Learning?, MIT Technology Review, MIT Technology Review, 17 November, available at: https://www.technologyreview.com/2018/11/17/103781/what-ismachine-learning-we-drew-you-another-flowchart/(accessed 13 May 2021).

Homans, G.C. (1961), Social Behavior: Its Elementary Forms, Routledge and Paul, London.

Hossain, M. and Oparaocha, G.O. (2017), "Crowdfunding: motives, definitions, typology and ethical challenges”, Entrepreneurship Research Journal, Vol. 7 No. 2, doi: 10.1515/erj-2015-0045.

Hui, J.S., Greenberg, M.D. and Gerber, E.M. (2014), "Understanding the role of community in crowdfunding work", Proceedings of the 17th ACM Conference on Computer Supported Cooperative Work and Social Computing, doi: 10.1145/2531602.2531715.

Jian, L. and Shin, J. (2015), "Motivations behind donors' contributions to crowdfunded journalism”, Mass Communication and Society, Vol. 18 No. 2, pp. 165-185, doi: 10.1080/15205436.2014. 911328.

Jian, L. and Usher, N. (2013), “Crowd-funded journalism", Journal of Computer-Mediated Communication, Vol. 19 No. 2, pp. 155-170, doi: 10.1111/jcc4.12051. 
Keongtae, K. and Visawanathan, S. (2019), "The experts in the crowd: the role of experienced investors in a crowdfunding market", MIS Quarterly, Vol. 43 No. 2, pp. 347-372, doi: 10.25300/misq/ 2019/13758.

Kickstarter.com (2019), "Kickstarter”, available at: http://www.kickstarter.com/help/stats (accessed 29 December 2020).

Entrepreneurial crowdfunding backer motivations

Kleemann, F. and Voss, G. (2008), "Un(der) paid Innovators: the commercial utilization of consumer work through crowdsourcing", Science, Technology and Innovation Studies, Vol. 4 No. 1, pp. 5-26, doi: 10.17877/DE290R-12790.

Kshetri, N. (2015), "Success of crowd-based online technology in fundraising: an institutional perspective", Journal of International Management, Vol. 21 No. 2, pp. 100-116, doi: 10.1016/j. intman.2015.03.004.

Lamphere, C. (2018), "Sharing is caring: crowdfunding's transformation of fundraising and the rise of the sharing economy", Information Today, Vol. 35 No. 4, p. 1.

Landy, F.J. (1989), Psychology of Work Behaviour, Brooks/Cole Publ, Pacific Grove, Calif.

Learnbonds.com (2020), Global Crowdfunding Transaction Value to Top \$12bn by 2023: Outsourcing Portal - Outsourcing Industry Portal, Outsourcing Portal, 16 March, available at: http://www. outsourcingportal.eu/en/global-crowdfunding-transaction-value-to-top-12bn-by-2023 (accessed 28 December 2020).

LeBon, G. (1896), The Crowd: A Study of the Popular Mind, Macmillan, New York, NY.

Lehner, O.M. (2013), "Crowdfunding social ventures: a model and research agenda”, Venture Capital, Vol. 15 No. 4, pp. 289-311, doi: 10.1080/13691066.2013.782624.

Lehner, O.M., Grabmann, E. and Ennsgraber, C. (2015), "Entrepreneurial implications of crowdfunding as alternative funding source for innovations", Venture Capital, Vol. 17 Nos 1-2, pp. 171-189, doi: 10.1080/13691066.2015.1037132.

Li, G. and Wang, J. (2019), "Threshold effects on backer motivations in reward-based crowdfunding”, Journal of Management Information Systems, Vol. 36 No. 2, pp. 546-573, doi: 10.1080/07421222. 2019.1599499.

Li, Y.-M., Liou, J.H. and Li, Y.-W. (2020), "A social recommendation approach for reward-based crowdfunding campaigns", Information and Management, Vol. 57 No. 7, p. 103246, doi: 10.1016/ j.im.2019.103246.

Lin, M., Prabhala, N.R. and Viswanathan, S. (2013), "Judging borrowers by the company they keep: friendship networks and information asymmetry in online peer-to-peer lending", Management Science, Vol. 59 No. 1, pp. 17-35, doi: 10.1287/mnsc.1120.1560.

Lipusch, N., Dellermann, D., Bretschneider, U., Ebel, P. and Leimeister, J.M. (2020), "Designing for crowdfunding Co-creation”, Business and Information Systems Engineering, Vol. 62 No. 6, pp. 483-499, doi: 10.1007/s12599-019-00628-w.

Lukkarinen, A., Teich, J.E., Wallenius, H. and Wallenius, J. (2016), "Success drivers of online equity crowdfunding campaigns”, Decision Support Systems, Vol. 87, pp. 26-38, doi: 10.1016/j.dss.2016. 04.006 .

Martinez-Canas, R., Ruiz-Palomino, P. and Pozo-Rubio, R.D. (2012), "Crowdfunding and social networks in the music industry: implications for entrepreneurship", International Business and Economics Research Journal (IBER), Vol. 11 No. 13, pp. 1471-1476.

Maslow, A.H. (1943), “A theory of human motivation”, Psychological Review, Vol. 50 No. 4, pp. 370-396, doi: $10.1037 / \mathrm{h} 0054346$.

Mausner, B. (1972), "Existence, relatedness and growth: human needs in organizational settings (book)", Personnel Psychology, Vol. 25 No. 4, pp. 734-736.

Meer, J. (2014), "Effects of the price of charitable giving: evidence from an online crowdfunding platform”, Journal of Economic Behavior and Organization, Vol. 103, pp. 113-124, doi: 10.1016/j. jebo.2014.04.010. 
EJIM

25,6

Meyer, J.P. and Allen, N.J. (1991), "A three-component conceptualization of organizational commitment”, Human Resource Management Review, Vol. 1 No. 1, pp. 61-89, doi: 10.1016/ 1053-4822(91)90011-z.

Miles, M.B. and Huberman, A.M. (1994), Qualitative Data Analysis: An Expanded Sourcebook, Sage, Thousand Oaks, CA.

Mollick, E. (2014), "The dynamics of crowdfunding: an exploratory study", Journal of Business Venturing, Vol. 29 No. 1, pp. 1-16, doi: 10.1016/j.jbusvent.2013.06.005.

Mollick, E. and Robb, A. (2016), "Democratizing innovation and capital access: the role of crowdfunding”, California Management Review, Vol. 58 No. 2, pp. 72-87, doi: 10.1525/cmr.2016. 58.2.72.

Moritz, A. and Block, J.H. (2014), "Crowdfunding: a literature review and research directions", SSRN Electronic Journal. doi: 10.2139/ssrn.2554444.

Organisciak, P. (2010), Why Bother?: Examining the Motivations of Users in Large-Scale CrowdPowered Online Initiatives, Thesis, University of Alberta, Edmonton, Alta.

Pietro, F.D., Bogers, M.L.A.M. and Prencipe, A. (2021), "Organisational barriers and bridges to crowd openness in equity crowdfunding", Technological Forecasting and Social Change, Vol. 162, p. 120388, doi: 10.1016/j.techfore.2020.120388.

Ribeiro-Navarrete, S., Palacios-Marqués, D., Lassala, C. and Ulrich, K. (2021), "Key factors of information management for crowdfunding investor satisfaction", International Journal of Information Management, Vol. 59, p. 102354, doi: 10.1016/j.ijinfomgt.2021.102354.

Ries, E. (2011), The Lean Startup: How Today's Entrepreneurs Use Continuous Innovation to Create Redically Successful Businesses, Crown Business, New York.

Salehan, M. and Kim, D.J. (2016), "Predicting the performance of online consumer reviews: a sentiment mining approach to big data analytics", Decision Support Systems, Vol. 81, pp. 30-40, doi: 10. 1016/j.dss.2015.10.006.

Schouten, K. and Frasincar, F. (2016), "Survey on aspect-level sentiment analysis", IEEE Transactions on Knowledge and Data Engineering, Vol. 28 No. 3, pp. 813-830, doi: 10.1109/tkde.2015.2485209.

Schroter, W. (2014), Top 10 Business Crowdfunding Campaigns of All Time, Forbes, Forbes Magazine, 16 April, available at: http://www.forbes.com/sites/wilschroter/2014/04/16/top-10-businesscrowdfunding-campaigns-of-all-time/?sh=7e15c0383e9f (accessed 28 December 2020).

Schwienbacher, A. and Larralde, B. (2010), "Crowdfunding of small entrepreneurial ventures", SSRN Electronic Journal, Vol. 10, doi: 10.2139/ssrn.1699183.

Short, J.C., Ketchen, D.J., McKenny, A.F., Allison, T.H. and Ireland, R.D. (2016), "Research on crowdfunding: reviewing the (very recent) past and celebrating the present", Entrepreneurship Theory and Practice, Vol. 41 No. 2, pp. 149-160, doi: 10.1111/etap.12270.

St John, J., Guynes, C.S. and Vedder, R. (2014), "The client-vendor offshore relationship: success factors", Information Systems Management, Vol. 31 No. 2, pp. 120-125, doi: 10.1080/10580530. 2014.890429.

Sun, J. and Teng, J.T.C. (2017), "The construct of information systems use benefits: theoretical explication of its underlying dimensions and the development of a measurement scale", International Journal of Information Management, Vol. 37 No. 5, pp. 400-416, doi: 10.1016/j. ijinfomgt.2017.04.010.

Tether, B.S. (2002), "Who co-operates for innovation, and why", Research Policy, Vol. 31 No. 6, pp. 947-967, doi: 10.1016/s0048-7333(01)00172-x.

Ullah, R., Amblee, N., Kim, W. and Lee, H. (2016), "From valence to emotions: exploring the distribution of emotions in online product reviews", Decision Support Systems, Vol. 81, pp. 41-53, doi: 10.1016/j.dss.2015.10.007.

Urquhart, C. (2001), “An encounter with grounded theory”, Qualitative Research in IS, pp. 104-140, doi: 10.4018/978-1-930708-06-8.ch005. 
Winerman, L. (2005), “The mind's mirror", Monitor on Psychology, American Psychological Association, October, available at: http://www.apa.org/monitor/oct05/mirror (accessed 28 December 2020).

Yuan, H., Lau, R.Y.K. and Xu, W. (2016), "The determinants of crowdfunding success: a semantic text analytics approach”, Decision Support Systems, Vol. 91, pp. 67-76, doi: 10.1016/j.dss.2016.08.001.

Entrepreneurial crowdfunding backer motivations

Zeng, S.X., Xie, X.M. and Tam, C.M. (2010), "Relationship between cooperation networks and innovation performance of SMEs", Technovation, Vol. 30 No. 3, pp. 181-194, doi: 10.1016/j. technovation.2009.08.003.

Zhang, H. and Chen, W. (2018), "Backer motivation in crowdfunding new product ideas: is it about you or is it about me?”, Journal of Product Innovation Management, Vol. 36 No. 2, pp. 241-262, doi: 10.1111/jpim.12477.

Zhang, P., Small, R., Dran, G.V. and Barcellos, S. (1999), "Websites that satisfy users: a theoretical framework for Web user interface design and evaluation", Proceedings of the 32nd Annual Hawaii International Conference on Systems Sciences. 1999. HICSS-32. Abstracts and CD-ROM of Full Papers, doi:10.1109/hicss.1999.772668.

Zhang, K.Z.K., Zhao, S.J., Cheung, C.M.K. and Lee, M.K.O. (2014), "Examining the influence of online reviews on consumers' decision-making: a heuristic-systematic model", Decision Support Systems, Vol. 67, pp. 78-89, doi: 10.1016/j.dss.2014.08.005.

Zheng, H., Li, D., Wu, J. and $\mathrm{Xu}, \mathrm{Y}$. (2014), "The role of multidimensional social capital in crowdfunding: a comparative study in China and US", Information and Management, Vol. 51 No. 4, pp. 488-496, doi: 10.1016/j.im.2014.03.003.

Joseph Pulitzer (2015), National Parks Service, US Department of the Interior, 26 February, available at: http://www.nps.gov/stli/learn/historyculture/joseph-pulitzer.htm (accessed 28 December 2020).

\section{Corresponding author}

Jeremy St John can be contacted at: jeremy.stjohn@angelo.edu

For instructions on how to order reprints of this article, please visit our website:

www.emeraldgrouppublishing.com/licensing/reprints.htm

Or contact us for further details: permissions@emeraldinsight.com 